\title{
A Relação entre Eficácia Coletiva de Professores e Percepção de Apoios na Escola
}

\author{
Karina Botti-Manoel - Universidade Estadual de Londrina, Londrina, Brasil \\ José Aloyseo Bzuneck - Universidade Estadual de Londrina, Londrina, Brasil \\ Fabio Alexandre Pereira Scacchetti - Universidade Tecnológica Federal do Paraná, Curitiba, Brasil
}

\begin{abstract}
Resumo
O presente estudo teve por objetivo investigar a eficácia coletiva de professores $(n=333)$ e sua associação com percepções de apoio no contexto escolar. Foram comparados professores que atuavam em escolas públicas com níveis diferenciados de desempenho pelo IDEB, bem como novatos versus experientes. Uma análise fatorial da escala tipo Likert indicou uma estrutura de dois fatores relativos, respectivamente, à eficácia coletiva e percepções de apoio, com alta consistência interna. Como resultado, identificaram-se relações positivas entre ambos os constructos. Além disso, as análises de variância revelaram que professores mais experientes e de escolas com altos escores no IDEB apresentaram crenças de eficácia coletiva mais robustas e mais altos níveis de percepções de apoio, quando comparados a professores menos experientes e de escolas com baixo IDEB. Os resultados foram discutidos à luz da Teoria Social Cognitiva, comparados com outras pesquisas e foram levantadas sugestões de novos estudos na área.
\end{abstract}

Palavras-chave: eficácia coletiva de professores, percepção de apoios, ensino fundamental, desempenho de alunos

The Relationship between Teachers' Collective Efficacy and Support Perception in the School

\begin{abstract}
The main objective of this study was to investigate teachers' $(n=333)$ collective efficacy, and their relationships with perceptions of support at school. Teachers who worked in high achieving public elementary schools were compared to those from low achieving schools, and novice versus experienced teachers, as well. Schools' achievement level was assessed by national Basic Education Development Index (IDEB). A Likert-type scale was submitted to factor analysis that showed a two-factor structure related to collective efficacy and perceptions of support, respectively, and with high internal consistency. As results, positive relationships between these constructs were identified. Moreover, variance analysis disclosed more robust collective efficacy beliefs and a higher level of support perception among more experienced teachers and among those from highly achieving schools when compared to their counterparts. Results were discussed in the light of the Social Cognitive Theory and compared with other studies, and directions for new studies were proposed, as well.

Keywords: teachers' collective efficacy, support perceptions, elementary school, students' performance
\end{abstract}

\section{Relación entre Eficacia Colectiva de Maestros y Percepción de Apoyo en las Escuelas}

\begin{abstract}
Resumen
El objetivo de este estudio fue investigar la eficacia colectiva de maestros $(n=333)$ y su asociación con percepciones de apoyo en el contexto escolar. Fueron comparados maestros de escuelas públicas con distintos niveles de desempeño académico, así como maestros novatos y maestros con más tiempo en la enseñanza. El rendimiento de las escuelas fue medido por el Índice de Desarrollo de Educación Básica - IDEB, un índice nacional. Un análisis factorial de la escala tipo Likert indicó una estructura de dos factores relativos, respectivamente, eficacia colectiva y percepciones de apoyo, con elevada consistencia interna. Como resultado, fueran identificadas relaciones positivas entre los dos constructos. Además, análisis de varianza demostraron que maestros con más tiempo en la enseñanza y de escuelas con mejor desempeño según el índice IDEB, presentaron niveles más elevados de eficacia colectiva y percepción de apoyo, al ser comparados con maestros de menos experiencia y de escuelas con desempeño más bajo según el IDEB. Los resultados fueron discutidos con base en la literatura de la Teoría Social Cognitiva, comparados con otros estudios y fueron levantadas sugestiones de nuevos estudios en el área.

Palabras clave: eficacia colectiva de maestros, percepciones de apoyo, enseñanza primaria, desempeño de alumnos
\end{abstract}

A motivação dos professores tem sido estudada à luz das mesmas teorias que orientam a pesquisa sobre motivação de alunos (Holzberger et al., 2013), tais como a teoria de metas de realização, a das atribuições causais, a teoria da autodeterminação e a teoria social cognitiva. As crenças de autoeficácia e de eficácia coletiva, dois construtos derivados da teoria social cognitiva de Bandura (1986; 1997; 2008), figuram entre os construtos motivacionais mais explorados em relação à atividade docente. Propôs-se, no presente estudo, explorar especificamente as crenças de eficácia coletiva de professores, definida por Goddard, Hoy e Woolfolk Hoy (2004, p. 4) como "os julgamentos dos professores de uma escola de que o seu conjunto é capaz de organizar e executar os cursos de ação exigidos para se conseguirem resultados positivos com seus alunos". Dessa forma, eficácia coletiva consiste na percepção individual sobre a capacidade de todo 
um grupo no qual está inserido, ou seja, cada professor revelará sua percepção não sobre si próprio, mas sobre o conjunto de professores, ou seja, sobre o "nós" (Bandura, 1997; 2008).

Os estudos sobre eficácia coletiva de professores eram escassos nos últimos anos do século 20 (Bandura, 1997; Goddard, 2001). Embora, mais recentemente, vários pesquisadores tenham trabalhado com esse construto, Klassen, Tze, Betts e Gordon (2011) observaram que a pesquisa sobre eficácia coletiva tem crescido, mas, em comparação com os avanços dos estudos sobre autoeficácia, ainda se encontraria apenas no limiar da maturidade. Os mesmos autores identificaram, em sua revisão da literatura, que certos questionários continham itens supostamente representativos de eficácia coletiva, mas que não atendiam ao pressuposto teórico do construto. Além disso, foi apontada a ocorrência de poucos estudos qualitativos ou longitudinais e, especialmente, o reduzido número de estudos que tenham examinado a influência de fatores contextuais sobre a eficácia coletiva.

Ao adotarem como foco a eficácia coletiva, os pesquisadores têm descoberto, em geral pelas análises de sendas e de regressão linear, associações positivas entre eficácia coletiva de professores e melhor desempenho acadêmico de alunos, em diferentes disciplinas e com maior peso do que o nível socioeconômico (por exemplo, Bandura, 1993; Goddard, 2001; Parker, Hannah, \& Topping, 2006; Tschannen-Moran \& Barr, 2004). Em particular, descobriu-se que eficácia coletiva dos professores tem valor positivo de predição para desempenho dos alunos em matemática (Goddard, 2002), em linguagem (Moolenaar; Sleegers, \& Daly, 2012) e sobre o desempenho acadêmico das escolas (Guerreiro-Casanova, 2013). Outros estudos têm evidenciado a influência da eficácia coletiva de professores sobre seu comprometimento afetivo com a escola e com satisfação no trabalho (Caprara, Barbaranelli, Borgogni, \& Stecaet, 2003), bem sobre autoeficácia quanto a usar boas estratégias de ensinar, quanto a envolver os alunos e quanto a manejo de classe (Ciani, Summers, \& Easter, 2008), com o comprometimento dos professores com a profissão e com propósito de nela permanecerem (Ware \& Kitsantas, 2007).

Em síntese, a literatura tem fornecido evidências de que as crenças de eficácia coletiva representam fator positivo tanto para os próprios professores como para as escolas e os alunos. De acordo com Bandura (1997; 2008; ver também Caprara et al., 2003), a eficácia coletiva exerce influência positiva, no conjunto de professores, sobre o grau de esforço, de buscas por inovação, de perseverança e de resiliência, mesmo diante de impedimentos e dificuldades. Mais ainda, crenças robustas na eficácia coletiva resultam num compromisso compartilhado dos individíduos em direção a objetivos comuns da escola. Tais resultados, portanto, favorecem claramente a conclusão de que "quanto mais alto for o senso de eficácia coletiva, melhor será o desempenho do grupo" (Bandura, 1997, p. 470).

\section{Fontes da Eficácia Coletiva}

Em outra linha de investigação, estudiosos têm-se voltado para identificar as fontes da eficácia coletiva. Bandura (1997; 2008) havia proposto que os mesmos quatro fatores que dão origem à autoeficácia, em sentido autorreferenciado, são igualmente críticos para a formação da eficácia coletiva. Assim, para desenvolvê-la e mantê-la, são consideradas como particularmente eficazes as experiências de êxito da escola como um todo (Adams \& Forsyth, 2006; Goddard, 2001; Goddard \& Skrla, 2006; Zambo \& Zambo, 2008), seguidas de experiências vicárias pela observação de colegas como modelos de sucesso e as várias formas de persuasão social advindas de outras pessoas, entre as quais se destaca o fornecimento de feedback positivo. Por último, tem base teórica a suposição de que a eficácia coletiva se alimenta de sentimentos partilhados de satisfação e bem-estar. Assim, por exemplo, os professores de uma escola se sentirão felizes e realizados porque seus alunos apresentaram altos escores em algum exame nacional e essa experiência afetiva contribuirá para o senso de eficácia coletiva.

Cada uma dessas quatro fontes, sempre que mentalmente evocadas, são interpretadas pelos professores, quando se depararem com determinadas situações concretas. Isto é, para Bandura (1997), nenhuma das fontes tem efeito direto na formação das crenças de eficácia, mas passam por um processamento cognitivo e só então afetam as percepções de eficácia para realizar ações futuras.

Crenças de autoeficácia dos indivíduos também favorecem o desenvolvimento da eficácia coletiva (por ex., Caprara et al., 2003; Guerreiro-Casanova, 2013; Stephanou, Gkavras, \& Doulkeridou, 2013). Bandura (1997; 2008). Destacou-se ainda que a eficácia coletiva é afetada, sobremaneira, pela qualidade das interações no seio do grupo, o que foi comprovado em estudos como os de Adams e Forsyth (2006), Ciani, Summers e Easter (2008) e Moolenaar, Sleegers e Daly (2012). Em particular, Adams e Forsyth (2006) descobriram pela análise 
de sendas que mais do que experiências anteriores de êxito e além do clima de colaboração entre os professores, uma estrutura de regras flexíveis na escola tem o maior efeito positivo direto sobre a eficácia coletiva de professores. Por fim, sobre a relação entre as quatro fontes da eficácia coletiva propostas originalmente por Bandura (1997) e outras modalidades do contexto, Adams e Forsyth (2006) propuseram a interpretação de que as primeiras representam fontes remotas, enquanto que, para o julgamento de capacidades coletivas para colocar ações sugeridas pela análise da tarefa, atuariam também fatores contextuais, como fontes próximas.

Em síntese, a literatura já apresenta apreciável conjunto de evidências da relevância da eficácia coletiva no contexto educativo, dadas as suas relações com o comprometimento dos professores e desempenho dos alunos. Por outro lado, ao descreverem, há alguns anos atrás, o panorama internacional de pesquisas nessa área, Goddard e Skrla (2006) observaram ter corrido menor esforço dos pesquisadores por identificar fatores de influência sobre as percepções de eficácia coletiva. No contexto brasileiro, abre-se ainda amplo espaço para se investigar as crenças de eficácia coletiva de professores, com atenção especial à percepção de variáveis socioambientais que lhes possam estar associadas.

Assim, a presente pesquisa, com abordagem correlacional, teve por objetivo geral explorar os níveis de eficácia coletiva de professores e sua relação com percepção de apoios na escola. Como objetivos específicos, buscou-se (1) levantar evidências de validade psicométrica de um instrumento de medida da eficácia coletiva e de percepção de apoios na escola; (2) relacionar os escores de percepção de apoios com os de eficácia coletiva; e (3) comparar os escores nessas duas medidas em função do desempenho de suas escolas avaliado pelo IDEB, bem como em função da condição do tempo de ensino.

\section{Método}

\section{Participantes}

Para a constituição da amostra, estabeleceu-se contato prévio com as direções de 20 escolas públicas do ensino fundamental I, escolhidas aleatoriamente de três cidades da região norte-paranaense, que apresentassem notas diferenciadas pelo IDEB 2011, o último disponível na época (BRASIL/MEC/INEP, 2012). Dessas 20 escolas, houve condições reais para a pesquisa em 18, nas quais atuavam 569 professores, dos quais 333 preencheram os questionários. Do total de escolas, a sete havia sido atribuída nota igual a 5,0 ou mais pelo IDEB, com 153 professores a participarem do estudo. Outras 11 escolas, com notas pelo IEDB entre 2,0 e 4,0 forneceram 180, compondo o total de 333 participantes. De todas as 18 escolas, 12 situavam-se em uma cidade de médio porte e outras seis, em duas pequenas cidades da mesma região. Como particularidade, 10, das 11 escolas que apresentam nota baixa pelo IDEB, localizavam-se em regiões periféricas das cidades, atendendo a uma população de nível socioeconômico geralmente baixo.

Todos os professores lecionavam no ensino fundamental I, sendo que 51 deles $(15,3 \%)$, apenas nesse nível de escolaridade. Outros 69 professores $(20,7 \%)$ lecionavam também no ensino fundamental II e, por fim, 188 (57\%) declararam atuar também no ensino médio. Uma parcela de 25 participantes $(7,5 \%)$ não marcou esse item. Em relação ao sexo, 85 eram homens $(25,5 \%)$ e 245 , mulheres $(73,5 \%)$; outros três não responderam. A maioria dos professores da amostra $(n=191$, ou seja, $57,3 \%)$ atuava no ensino há mais de dez anos.

\section{Instrumentos}

No questionário aplicado aos professores, solicitavam-se, de início, seus dados pessoais como tempo de serviço, gênero e nível de ensino em que atuavam. Um questionário composto de duas escalas foi utilizado para a coleta de dados. Para a avaliação da eficácia coletiva, foi aplicada a escala criada anteriormente por Bzuneck, Boruchovitch e Rufini (2014). A análise pelos componentes principais revelou nessa medida uma estrutura unifatorial com boas propriedades psicométricas, incluindo alfa $=0,95$. Era composta de 22 itens em escala Likert, com cinco alternativas de respostas, desde nada capaz̧es (peso 1) até plenamente capažes (peso 5). Um exemplo de item: "Na minha visão, os professores/professoras de minha escola são capazes de motivar até alunos bem desmotivados e resistentes".

Uma segunda escala foi criada pela primeira autora para avaliar a percepção da disponibilidade de apoios por parte de pessoas ligadas à escola. Formavam esse instrumento quatro itens a serem respondidos também em escala Likert de cinco pontos, desde nenbum apoio (peso 1) até muito apoio (peso 5). Para sua construção, serviram de base questionários dos estudos de Skaalvik e Skaalvik (2011) e de Tschannen-Moran e Woolfolk Hoy (2006). Um exemplo de item: "Qual o grau de apoio que você recebe em seu trabalho por parte da direção e da equipe pedagógica?”. 


\section{Procedimentos}

O projeto desta pesquisa foi submetido ao Comitê de Ética em Pesquisa da Universidade Estadual de Londrina e aprovado sob o número 033/2013. As direções de cada escola, além das secretarias municipais de educação, formalizaram seu consentimento com a realização do estudo e autorizaram o acesso aos respectivos professores para a entrega e recebimento dos protocolos de resposta. Os participantes declararam, por ocasião da coleta de dados, responder aos questionários de forma espontânea, por meio do Termo de Consentimento Livre e Esclarecido.

Para a coleta de dados foram adotadas duas modalidades. Na primeira, em dias e horários disponibilizados pelos gestores, a primeira autora fazia-se pessoalmente presente em reuniões pedagógicas ou de outra natureza e, na ocasião, aplicava os questionários de forma coletiva, com as instruções oportunas sobre como responder, e que seria mantido o sigilo das respostas, sempre anônimas. Todos foram orientados a marcar nos itens do questionário, considerando a escola em que se encontravam na ocasião, mesmo que atuassem em mais de uma instituição. Foi também reiterado o caráter voluntário da participação. Em cada caso de aplicação coletiva, ao final de cerca de 20 minutos, os protocolos preenchidos pela totalidade dos presentes podiam ser todos recolhidos. A aplicadora pôde observar que muitos, por verbalizações e pela expressão corporal, demonstravam má vontade em preencher os protocolos, um fato mais frequente nas escolas de baixo IDEB. Mas, no final, todos os completavam e entregavam.

Nem sempre foi possível a aplicação na modalidade coletiva e presencial, o que ocorreu quando os diretores autorizaram a coleta, porém, não disponibilizavam o tempo para a aplicação no espaço da escola. Nesses casos, com as mesmas orientações feitas na aplicação coletiva, os questionários eram entregues aos professores para responderem individualmente, a qualquer hora, mesmo em casa. Essa condição obrigou o deslocamento recorrente da pesquisadora à mesma instituição para o recolhimento, mas foram resgatados apenas 20\% desses protocolos distribuídos. O total de questionários preenchidos atingiu o número de 333, incluindo aqueles provenientes das aplicações coletivas nas escolas.

\section{Procedimentos de Análise}

As respostas constantes dos protocolos foram organizadas em planilha Excel e submetidos a tratamentos estatísticos com o uso do programa estatístico SPSS. Os dados relativos ao questionário que se referia aos dois construtos, eficácia coletiva e percepção de apoios, foram submetidos à análise pelos componentes principais. As 18 escolas do ensino fundamental I foram consideradas como unidades de análise, com seus respectivos professores. Nessa fase, foram aproveitados apenas 324 protocolos, já que nove deles haviam sido descartados por apresentarem muitos dados incompletos. Em seguida, foram levantadas as médias grupais da amostra final de 324 participantes em eficácia coletiva e percepção de apoios e buscada a relação funcional com o tipo de escola em função da nota do IDEB e com tempo de serviço.

\section{Resultados}

Os resultados serão descritos segundo a ordem dos objetivos definidos para o presente estudo, a começar pelas características do questionário utilizado. Inicialmente, os dados obtidos por ambas as escalas, originados de 324 protocolos completos, foram submetidos ao Teste de Esfericidade de Bartlett, pelo qual surgiu uma matriz de correlações favorável entre os itens: $\left(\chi^{2}[325 ; n=333]=5423,494 ; p<0,001\right)$. A medida de adequação da amostra foi examinada com o índice de Kaiser-Meyer-Olkin (KMO = 0,95). Com esses resultados, viabilizou-se a execução da análise fatorial subsequente.

A análise fatorial foi feita pela extração dos componentes principais e com rotação Varimax, respeitado o critério básico de eigenvalues acima de 1,0. A Tabela 1 apresenta a distribuição final dos itens por fator e suas respectivas cargas fatoriais.

Da escala original de eficácia coletiva com 22 itens, a presente análise fatorial concluiu que seis itens carregavam, pelo valor de corte de 0,30 , em dois fatores simultaneamente, ou seja, os itens 2, 13, 19, 20, 21 e 22. Por exemplo, o item 19 estava assim redigido: "Em minha escola, os professores são capazes de trabalhar de modo cooperativo". Por se ter adotado o critério de carga exclusiva em um fator, esses seis itens foram excluídos da escala final e nas análises posteriores. Além disso, dois outros itens, 17 e 18, não carregaram nesse mesmo fator 1 , mas sim no fator 2. Por isso, ao fator 1 convergiram 14 itens da escala original, exclusiva e inequivocamente representativos de eficácia coletiva percebida. Já quanto aos itens 17 e 18, que migraram da primeira escala, julgou-se não serem conceitualmente pertinentes à medida de percepção de apoios, 
Tabela 1

Distribuição dos Itens por Fator e suas Respectivas Cargas Fatoriais

\begin{tabular}{|c|c|c|c|}
\hline Fatores & 1 & 2 & $\mathrm{~h}^{2}$ \\
\hline $\begin{array}{l}\text { 01. Acredito que os professores/professoras de minha escola são capazes de motivar } \\
\text { praticamente todos os alunos de suas classes. }\end{array}$ & 0,638 & & 0,463 \\
\hline $\begin{array}{l}\text { 03. Os professores/professoras de minha escola são capazes de manter normalmente } \\
\text { a disciplina em classe. }\end{array}$ & 0,599 & & 0,418 \\
\hline $\begin{array}{l}\text { 04. Os professores/professoras de minha escola são capazes de tornar os conteúdos } \\
\text { acessíveis a seus alunos. }\end{array}$ & 0,805 & & 0,663 \\
\hline $\begin{array}{l}\text { 05. Na minha opinião, os professores/professoras de minha escola são capazes de } \\
\text { usar métodos de ensino eficazes. }\end{array}$ & 0,788 & & 0,658 \\
\hline $\begin{array}{l}\text { 06. Os professores são capazes de criar um clima psicológico em que os alunos se } \\
\text { habituem a pensar. }\end{array}$ & 0,787 & & 0,669 \\
\hline $\begin{array}{l}\text { 07. Os professores são capazes de usar um novo método de ensinar quando não deu } \\
\text { resultado o que tiver usado. }\end{array}$ & 0,858 & & 0,756 \\
\hline 08. Os professores são capazes de tornar sua aula interessante, atraente. & 0,744 & & 0,632 \\
\hline $\begin{array}{l}\text { 09. Os professores são capazes de prestar ajuda eficaz quando os alunos mostram que } \\
\text { têm dificuldade. }\end{array}$ & 0,744 & & 0,615 \\
\hline 10. Os professores, em geral, são capazes de controlar alunos Indisciplinados. & 0,610 & & 0,472 \\
\hline $\begin{array}{l}\text { 11. Os professores são capazes de atender, em classe, alunos com necessidades } \\
\text { especiais da inclusão. }\end{array}$ & 0,458 & & 0,329 \\
\hline $\begin{array}{l}\text { 12. Os professores de minha escola são capazes de ajudar eficazmente alunos com } \\
\text { dificuldades de aprendizagem. }\end{array}$ & 0,687 & & 0,561 \\
\hline $\begin{array}{l}\text { 14. Em minha escola, os professores são capazes de fazer com que os alunos se } \\
\text { sintam bem acolhidos na escola. }\end{array}$ & 0,731 & & 0,626 \\
\hline $\begin{array}{l}\text { 15. Na minha opinião, os professores/professoras de minha escola são capazes de } \\
\text { usar métodos de ensino eficazes. }\end{array}$ & 0,600 & & 0,573 \\
\hline $\begin{array}{l}\text { 16. Os professores de minha escola são capazes de prevenir e lidar eficazmente com o } \\
\text { bullying na escola. }\end{array}$ & 0,458 & & 0,546 \\
\hline $\begin{array}{l}\text { 23. Qual é o grau de apoio que você recebe em seu trabalho por parte da Direção e } \\
\text { Equipe. }\end{array}$ & & 0,735 & 0,564 \\
\hline 24. Qual é o grau de apoio que você recebe em seu trabalho por parte dos colegas. & & 0,568 & 0,422 \\
\hline 25. Qual é o grau de apoio que você recebe em seu trabalho por parte dos pais. & & 0,697 & 0,496 \\
\hline 26. Qual é o grau de apoio que você recebe em seu trabalho por parte da comunidade. & & 0,685 & 0,513 \\
\hline
\end{tabular}

Nota. Os números dos itens do fator 1 são os mesmos da escala original de Bzuneck et al. (2014).

característica do fator 2 e, por isso, optou-se, também, por descartá-los dessa escala e nas análises seguintes. Em síntese, concluiu-se pela resolução de dois fatores, que explicavam $55 \%$ da variância total. Os valores de saturação em qualquer um dos dois fatores, que aparecem na Tabela 1 , variam desde 0,85 até um mínimo de 0,45 , valores de magnitude muito adequada. Como índices de consistência interna, o valor do alfa de Cronbach para o fator 1, com 14 itens, foi de 0,92 e, para o fator 2 , com os quatro itens originais, com alfa $=0,82$.

\section{Estatistica Descritiva}

Para a amostra total final $(n=324)$ a média na escala de eficácia coletiva foi de 43,4 $(D P=7,20)$, diante da pontuação máxima possível de 60,0 . Na medida de percepção de apoio a média foi 20,9 $(D P=3,72)$ para uma pontuação máxima possível de 30,0. As distribuições univariadas das duas variáveis revelaram-se aproximadamente normais. Cabe apontar ainda que, na medida de eficácia coletiva, $43,8 \%$ dos professores $(n=142)$ apresentaram 
pontuação inferior ao ponto médio da escala, que era 30,0. De modo similar, na medida de percepção de apoio, $46,5 \%(n=154)$ dos professores alcançaram pontuação inferior ao ponto médio.

Quanto às relações entre os escores grupais na percepção de eficácia coletiva e em percepção de apoios, surgiu uma correlação moderada: $r=0,55$ e $p$ $\leq 0,001$. Na sequência, aplicou-se também a análise de regressão linear, com o objetivo de investigar se a variável percepção de apoios tem valor de predição sobre a eficácia coletiva, como variável critério. Essa relação foi comprovada: $\beta=0,55 ; E P=0,09 ; ; p<0,001$.

Foi também objetivo específico desta pesquisa comparar, em relação às duas variáveis, os escores médios de professores provenientes de escolas com o IDEB baixo $(n=175)$ com os de professores de escolas com IDEB alto $(n=149)$. Na medida de eficácia coletiva, a média do primeiro grupo foi 41,18 (DP = $7,12)$, contra 46,02 $(D P=6,38)$ do segundo grupo. A diferença é estatisticamente significativa: $t=-6,37$ ( $p-$ $0,001)$. Da mesma forma, foi significativa a diferença entre as médias em percepção de apoios, com 19,38 $(D P=3,44)$ para o grupo de baixo IDEB e 22,82 $(D P=$ $3,10)$ para o grupo de alto IDEB: $t=-9,64(p=0,001)$. Em síntese, nas duas medidas, foram significativamente mais altas as médias do grupo de professores de escolas com IDEB alto.

A questão sobre a relação dos escores grupais nas duas variáveis com o tempo de exercício no magistério, optou-se por comparar professores identificados apenas nos dois extremos temporais: o daqueles com tempo de serviço até cinco anos e o daqueles com 15 anos ou mais. Entretanto, como este último grupo de participantes apresentava um número cerca de três vezes maior que o primeiro, procedeu-se a uma nova formação quantitativa. Assim, por seleção aleatória, constituiu-se um grupo de 54 professores com mais tempo de serviço, com procedência do tipo de escola - com IDEB alto ou baixo - equiparável à do grupo de professores com até cinco anos de trabalho $(N=$ 55). Como resultados, na medida de eficácia coletiva, o grupo de professores mais novos $(n=55)$ obteve média de 40,56 $(D P=8,47)$, enquanto que, no grupo de professores mais experientes, $(n=54)$ a média foi 44,33 $(D P=5,91)$, com a variância de $t=-2,68(p=0,008)$. Em percepção de apoios, surgiu média de 19,7 (DP = $3,51)$ para o grupo de professores com mais tempo de serviço, contra uma média de 21,1 $(D P=3,63)$ para o outro grupo, com diferença estatisticamente significativa entre ambos: $t=-2,08(p=0,04)$.

\section{Discussão}

O primeiro objetivo do estudo foi de natureza metodológica, ao se buscar reanalisar fatorialmente um instrumento brasileiro de medida da eficácia coletiva de professores e, conjuntamente, uma escala nova de percepção de apoios na escola. Problemas na mensuração da eficácia coletiva têm sido apontados na literatura (por exemplo, Klassen, Tze, Betts, \& Gordon, 2011) e, portanto, justifica-se todo empenho que conduza a refinamentos de seus instrumentos.

$\mathrm{Na}$ presente pesquisa, optou-se por aplicar aos participantes um conjunto de itens relativos a dois construtos de percepção social, conceitualmente distintos, ou seja, de eficácia coletiva e de percepção de apoios. O objetivo era verificar se a escala referente ao primeiro construto se manteria unifatorial, distinta da segunda, ou se formariam um único fator ou se resultariam mais fatores. Para a presente amostra, mais numerosa que a do estudo de Bzuneck et al. (2014), e melhor caracterizada pela restrição das categorias de professores, a escala de eficácia coletiva percebida, agora reduzida a apenas 14 itens, consolidou-se como unidimensional, fatorialmente distinta da de percepção de apoios, cujos quatro itens convergiram para um único fator subjacente. Em síntese, pela análise dos componentes principais, concluiu-se por evidências de propriedades psicométricas robustas de ambas as escalas.

Nas avaliações de eficácia coletiva de professores, alguns autores haviam concluído por uma estrutura bifatorial (por exemplo, Schechter \&Tschannen-Moran, 2006; Tschannen-Moran \& Barr, 2004). Já para outros, como Goddard et al. (2000), Skaalvik e Skaalvik (2007) e Ware e Kitsantas (2007) e, por último, Bzuneck et al. (2014), os itens de eficácia coletiva constituíam uma escala unifatorial. A análise fatorial confirmatória, aplicada por Skaalvik e Skaalvik (2007), manteve como unifatorial a subescala de eficácia coletiva, distinta da de autoeficácia com seis fatores, e de percepção de controle externo, um fator. Ware e Kitsantas (2007), pela análise dos componentes principais, também concluíram que os itens utilizados para avaliar eficácia coletiva convergiam para um único fator, distinto de outros dois fatores representativos de autoeficácia.

A resolução unifatorial do presente questionário de eficácia coletiva, contrastantes com as estruturas bifatoriais obtidas por outros autores revela que ainda perdura a necessidade de se buscar aprimoramentos nessa medida. Em particular, quanto à escala brasileira, 
sugere-se que sejam realizadas novas análises e com mais amostras.

Por outro lado, a correlação positiva moderada entre os escores grupais nas medidas de eficácia coletiva e de percepções de apoios mostra que se trata de construtos que compartilham algumas características, mas que, ao mesmo tempo, são independentes entre si. Em outras palavras, podem considerar-se medidas de dois construtos teoricamente distintos, porém relacionados. Como complemento, a análise de regressão revelou que percepção de apoio tem valor positivo de predição em relação à eficácia coletiva, isto é, pode-se prever que, caso se altere o valor da variável percepção de apoios, também haverá mudança na medida de eficácia coletiva.

O que, então, pode-se concluir com base em tais relações identificadas pelas presentes análises? Em outras palavras, o que significam as percepções de apoio na escola para o desenvolvimento da eficácia coletiva? A resposta a essas questões será encontrada na própria teoria de Bandura (1997: ver também Woolfolk Hoy, \& Spero, 2005). Segundo esses autores, percepções de formas diversas de apoio na escola equivalem a experiências de persuasão social, propostas por Bandura como uma das fontes das crenças de eficácia. Isso significa que o fato de se sentirem apoiados por colegas, gestores e outras pessoas representa para os professores uma mensagem de que ninguém está só no enfrentamento das dificuldades e desafios de sua função, mas que cada indivíduo e todo o grupo, em função dos apoios de outras pessoas, podem sentir-se capazes de exercer ações conducentes aos objetivos partilhados. Segundo a interpretação de Adams e Forsyth (2006), as influências contextuais de apoios atuariam como fontes próximas da eficácia coletiva, enquanto que a persuasão verbal seria a fonte remota, porém, inerente à situação.

Por outro lado, os itens de percepção de apoios, utilizados com a presente amostra (ver Tabela 1) sugerem, no seu conjunto, ser compatíveis com um dos componentes do que, na literatura, tem sido qualificado como clima psicológico da escola (por exemplo, Cohen, McCabe, Michelli, \& Pickeral, 2009; Collie, Shapka, \& Perry., 2012). Trata-se de um conceito que, segundo esses autores, inclui as dimensões de segurança física e emocional, qualidade do ensino, relações de colaboração e recursos materiais. Percepção de apoios seria uma modalidade de percepção de colaboração. Diversos estudos citados por esses autores apontaram relações positivas entre clima da escola percebido como negativo e burnout, e, quando positivo, associado a comprometimento e satisfação no trabalho. Essas associações sugerem que, em novas pesquisas, particularmente na área, examine-se especificamente a relação entre os diversos componentes de clima da escola, nesse momento incluindo apoio percebido, com eficácia coletiva.

Uma associação crítica identificada na presente pesquisa foi entre eficácia coletiva dos professores e percepção de apoios, por um lado, e o desempenho dos alunos em de cada escola, estabelecido com base nos resultados do IDEB. A análise de variância concluiu por diferenças estatisticamente significativas em função do tipo de escola, isto é, professores de escolas com IDEB mais baixo revelaram crenças mais reduzidas em eficácia coletiva, bem como percepções de menor apoio na escola, em comparação com os professores das escolas de IDEB alto. É um resultado que se alinha com os de outros estudos (por exemplo, de Goddard, 2001; e de Moolenar et al., 2012), nos quais também se descobriram relações estatisticamente significativas entre eficácia coletiva de professores e desempenho de alunos.

No presente caso, sem entrar na discussão sobre outras possíveis implicações das avaliações pelo IDEB (ver, por exemplo, Almeida, Dalben, \& Freitas, 2013), importa a constatação de que seus índices, altos ou baixos, têm um caráter público, representando um feedback à própria eficácia dos professores em relação às aprendizagens em sua escola. Todos os professores, assim como outros membros da comunidade, tomam conhecimento do nível de rendimento de sua escola por essa avaliação e, além disso, da de outras escolas, com as quais se comparam. Portanto, para os professores, em particular, trata-se de uma experiência compartilhada, respectivamente, de êxito ou de fracasso, que repercute diretamente sobre o desenvolvimento da eficácia coletiva. Para Bandura (1997), experiências de êxito representam o fator primordial e imprescindível para esse desenvolvimento. Todas as crenças de eficácia, segundo o mesmo autor, não são apenas crenças intrapessoais, mas construtos de caráter relacional, por serem sempre afetados pelo meio social e que, adicionalmente, podem nele influenciar funcionalmente. Assim, ao tomarem conhecimento dos resultados de seu ensino, no caso, pelas fontes oficiais do rendimento médio dos alunos, os professores processam essa informação, formando um julgamento sobre suas próprias capacidades e sobre as capacidades do grupo em relação a seu ensino. Nos casos de índices mais altos de rendimento dos alunos, o julgamento tenderá a ser positivo, ou seja, haverá mais concordância com o enunciado: "os professores de minha escola são capazes de...”. Julgamento 
diferente será formado quando for negativa a experiência em função dos baixos índices de rendimento dos alunos. Embora, nesses casos, os professores também possam atribuir a responsabilidade pelo fracasso de seus alunos a fatores externos a si próprios, em função do viés hedonístico (Weiner, 1984), não se descarta permanecer ainda viva a sensação de não terem sido capazes de, como grupo, enfrentarem com êxito essa condição negativa. Os presentes dados dão apoio a essa interpretação.

Um dos efeitos imediatos previsíveis do enfraquecimento das crenças de eficácia coletiva de professores é a queda da própria motivação, isto é, eles tendem a reduzir o empenho em promover a aprendizagem e a própria motivação de seus alunos. Mais especificamente, tendem a rebaixar, em nível coletivo, as metas educacionais da escola e os níveis de exigências em sala de aula (Bandura, 1997). Dessa forma, isso se configura em uma causação recíproca, no sentido de relação funcional (Bandura (2008), ou seja, fecha-se um círculo vicioso: baixo rendimento escolar dos alunos representa uma condição que, entre outras, tende a abalar as crenças de eficácia coletiva dos professores e, por essa razão, empenham-se menos, com a consequente manutenção de baixa qualidade das aprendizagens de seus alunos. É um processo em que a ineficácia se autoalimenta.

Na mesma linha, Takahashi (2011), comentado os resultados de seu estudo qualitativo com professoras de alunos de nível socioeconômico inferior, argumentou que é justamente com tais alunos que os professores precisam ser mais criativos, empenhados e persistentes. Paradoxalmente, segundo a mesma autora, as escolas que mais precisam de inovação e de senso de compromisso contam com educadores menos motivados para buscar soluções pertinentes. No presente estudo, dez das onze escolas que apresentaram nota baixa pelo IDEB, cujos professores se caracterizaram por crenças mais fracas de eficácia coletiva, atendiam a populações de periferia, de nível socioeconômico inferior. Precisamente nessas escolas é que se identificaram baixas percepções de apoio, associadas com experiências de certa ineficácia do ensino.

Por último, surgiram no presente estudo diferenças significativas entre os professores nas medidas de eficácia coletiva e de percepção de apoios, em função do tempo de exercício no ensino, controlada a condição de escola em função do nível do IDEB. Professores mais experientes apresentaram escores significativamente mais elevados nas duas variáveis. Especificamente para a eficácia coletiva, esses resultados são opostos aos de
Schechter e Tschannen-Moran (2006), mas alinha-se com o de Goddard e Skrla (2006) que, porém, identificaram efeito limitado dessa variável.

A presente pesquisa não forneceu dados que expliquem porque professores com 15 anos ou mais de ensino revelaram, em nível estatisticamente significativo, crenças mais robustas de eficácia coletiva, nem porque se sentem mais apoiados. Por hipótese, professores com menos experiência no ensino ou numa instituição, sentir-se-iam menos relacionados com os colegas de trabalho, sobre os quais, adicionalmente, teriam um conhecimento fragmentado. Em particular, é plausível que um sentimento de isolacionismo estaria na raiz das baixas percepções de apoio nesses contextos por parte dos professores iniciantes. Estudos posteriores poderiam examinar essa hipótese. A esse respeito, Moolenaar et al. (2012) sugeriram que, para se alimentar a eficácia coletiva, cada escola deve fomentar o compartilhamento habitual de experiências entre professores, juntamente com a formação de redes de estreito relacionamento entre eles, uma solução que provavelmente atenderá às necessidades dos professores recém-chegados.

Entre as limitações deste estudo e que poderão ser superadas em outros no futuro, a primeira reside no fato de que se considerou apenas o tempo de exercício dos professores no ensino e não especificamente na escola na qual o desempenho de alunos estava sendo considerado. Embora tenham sido orientados, na hora do preenchimento dos protocolos, de que deveriam ter em mente apenas a escola em que o questionário estava sendo aplicado e à qual estavam vinculados, não se levantou o tempo em que cada qual estava na referida escola. Assim, no presente caso, não se conhece a influência da atuação numa escola como distinta da atuação no ensino.

Pelo recorte adotado, foram englobadas numa única escala as percepções de apoios por parte de colegas, dos gestores, das famílias e da comunidade. Sugerem-se estudos em que sejam discriminadas essas diversas fontes, cujo peso de influência pode ser significativamente variado, também em função da localização das escolas.

Uma última limitação está ligada ao nível de desempenho acadêmico das escolas, aferido pelo IDEB. Embora se trate de um índice confiável, em outras investigações, pode ser aprofundado o conhecimento do fenômeno, buscando-se identificar também outras raízes do baixo desempenho de alunos de certas escolas e que independem dos seus atuais professores 
(Almeida et al., 2013). Em particular, que não se adote como pressuposto que o nível socioeconômico da clientela esteja invariavelmente vinculado a baixo desempenho escola.

\section{Considerações Finais}

Os resultados de estudos sobre eficácia coletiva de professores, nas últimas décadas, têm dado apoio à conclusão enfática de Bandura (1995) de que "as crenças coletivas de impotência são mais destrutivas que as próprias condições negativas do contexto" (p. 38). Trata-se de uma observação com elevado alcance prático, ao sugerir que particular atenção deve ser dada aos fatores que alimentam e desenvolvem a eficácia coletiva.

Os dados do presente estudo podem prestar uma pequena contribuição para o conhecimento de fontes desse construto, no contexto brasileiro. Ficou documentado que o nível de eficácia coletiva está positivamente relacionado com a percepção de apoios na escola e, mais ainda, pela análise de regressão, que os níveis de percepção de apoios têm valor de predição sobre eficácia coletiva. Além disso, os níveis de eficácia coletiva variaram em função das experiências de êxito junto aos alunos, indicado pelas avaliações oficiais de suas escolas.

Dessas constatações podem, brevemente, extrair-se duas linhas de atuação junto aos professores, colhendo sugestão de Henson (2001), entre outros. Embora esse autor tenha examinado especificamente o construto de autoeficácia, suas conclusões soam como igualmente oportunas quando se trata de eficácia coletiva. Pela sua proposta, em síntese, esforços em cada escola devem ser envidados pelos gestores no sentido de tornar o clima psicológico mais propício e, pela promoção do desenvolvimento profissional, melhorar as competências de ensino. Em última instância, essas providências teriam como consequência alimentar nos professores o senso de agência e as crenças de eficácia. Clima psicológico propício inclui cooperação e apoios e, por outro lado, competências são cruciais para o desempenho dos alunos que, em seguida, representarão experiências de êxito para os professores.

\section{Referências}

Adams, C. M., \& Forsyth, P. B. (2006). Proximate sources of collective teacher efficacy. Journal $f$ Educational Administration, 44 (6), 625-642. doi: 10.1108/09578230610704828
Almeida, L. C., Dalben, A., \& Freitas, L. C. (2013). O Ideb: Limites e ilusões de uma política educacional. Educaşão e Sociedade, 34(125), 1153-1174. doi: 10.1590/S0101-73302013000400008

Bandura, A. (1993). Perceived self-efficacy in cognitive development and functioning. Educational Psychologist, 28, 117-148. doi:10.1207/s15326985ep2802_3

Bandura, A. (1995). Exercise of personal and collective efficacy in changing societies. Em A. Bandura (Ed.) Self-efficacy in changing societies. (pp.1-45). New York, NY: Cambridge University Press.

Bandura, A. (1986). Social Foundations of Thought \& Action - A Social Cognitive Theory. Englewood Cliffs: Prentice Hall.

Bandura, A. (1997). Self-efficacy: The exercise of control. New York: W.H. Freeman and Company.

Bandura, A. (2008). O exercício da agência humana pela eficácia coletiva. Em A. Bandura, R. G. Azzi \& S. A. G. Polydoro (Eds.). Teoria social cognitiva: Conceitos básicos. (pp. 115-122). Porto Alegre: Artmed. (Tradução do original de 2000).

Brasil/MEC/INEP. Ministério da Educação, Instituto Nacional de Estudos e Pesquisas Educacionais Anísio Teixeira. (2012). Indice de Desenvolvimento da Educação Básica 2011. Brasília: MEC. Disponível em: http://ideb.inep.gov.br/Site.

Bzuneck, J.A., Boruchovitch, E., \& Rufini, S. E. (2014). Eficácia coletiva de professores: Evidências de validade de construto de um questionário. Avaliação Psicológica, 13(3), 427-435. Recuperado de http:// pepsic.bvsalud.org/pdf/avp/v13n3/v13n3a15. pdf

Caprara, G. V., Barbaranelli, C., Borgogni, L., \& Stecaet, P. (2003). Efficacy beliefs as determinants of teachers' job satisfaction. Journal of Educational Psychology, 95 (4), 821-832. Recuperado de http:/ / eric. ed.gov/?id=EJ678601

Ciani, K. D., Summers, J. J., Easter, M. A. (2008). A "top-down" analysis of high school teacher motivation. Contemporary Educational Psychology, 33, 533-560. doi:10.1016/j.cedpsych.2007.04.002

Cohen, J., McCabe, E. M., Michelli, N. M., \& Pickeral, T. (2009). School climate: Research, policy, practice, and teacher education. Teachers College Record, 111, 180-213. Recuperado de http://eric. ed.gov/?id=EJ826002 
Collie, R. C., Shapka, J. D., \&. Perry, N. E. (2012). School climate and social-emotional learning: Predicting teacher stress, job satisfaction, and teaching efficacy. Journal of Educational Psychology, 104 (4), 1189-1204. doi: 10.1037/a0029356

Goddard, R. D. (2001). Collective efficacy: A neglected construct in the study of schools and student achievement. Journal of Educational Psychology, 93, 467-476. doi: 10.1037/0022-0663.93.3.467

Goddard, R. D., Hoy, W. K., \& Woolfolk Hoy, A. (2000). Collective teacher efficacy: Its meaning, measure, and impact on student achievement. American Educational Research Journal, 37, 479-507.

Goddard. D., Hoy, W. K., \& Woolfolk-Hoy, A. (2004). Collective efficacy beliefs: Theoretical developments, empirical evidence, and future directions. Educational Researcher, 33, 3-3. doi: 10.3102/0013189X033003003

Goddard, R. D., \& Skrla, L. (2006). The influence of school social context on teachers' collective efficacy beliefs. Educational Administration Quarterly, 42,(2), 216-235. Recuperado de http://eric. ed.gov/?id=EJ734916

Guerreiro-Casanova, D. C. (2013). Crenças de eficácia de gestores escolares e de docentes no ensino médio paulista (tese de doutorado em Educação). Universidade Estadual de Campinas, Campinas-SP.

Henson, R. K. (2001). The effects of participation in teacher research on teacher efficacy. Teaching and Teacher Education, 17, 819-836. Recuperado de http:/ / eric.ed.gov/?id=EJ640151

Holzberger, D., Philipp, A., \& Kunter, M. (2013). How teachers' self-efficacy is related to instructional quality: A longitudinal analysis. Journal of Educational Psychology, 105(3) 774-786. Recuperado de http:/ / eric.ed.gov/?q=classroom + management\& ff1 $=$ subStudent + Evaluation\&id $=$ EJ1054510

Klassen, R. M., Tze, V. M. C., Betts, S. M., \& Gordon, K. A. (2011). Teacher efficacy research 1998-2009: Signs of progress or unfulfilled promise? Educational Psychology Review. 23, 21-43. Recuperado de http://link.springer.com/article/10.1007\%2 Fs10648-010-9141-8

Moolenaar, N. M., Sleegers, P. J., \& Daly, A. J. (2012). Taming up: Linking collaboration networks, collective efficacy and student achievement. Teaching and Teacher Education: An International Journal of Research and Studies, 28(2), 251-262. doi: 10.1016/j. tate.2011.10.001

Parker, K., Hannah, E., \& Topping, K. J. (2006). Collective teacher efficacy, pupil attainment and socio-economic status in primary school. Improving Schools, 9, 111-129. doi: 10.1177/1365480206064965

Schechter, C., \& Tschannen-Moran, M. (2006). Teachers' sense of collective efficacy: An international view. International Journal of Educational Management, 20, 480-489. Recuperado de http:// eric.ed.gov/?id $=\mathrm{EJ} 801590$

Skaalvik, E. M., \& Skaalvik, S. (2007). Dimensions of teacher self-efficacy and relations with strain factors, perceived collective teacher efficacy, and teacher burnout. Journal of Educational Psychology, 99(3), 611-625. doi: 10.1037/0022-0663.99.3.611

Skaalvik, E. M., \& Skaalvik, S. (2010).Teacher self-efficacy and teacher burnout: A study of relations. Teacher and Teacher Education, 26, 1059-1069. doi:10.1016/j.tate.2009.11.001

Skaalvik, E. M., \& Skaalvik, S. (2011). Teacher job satisfaction and motivation to leave the teaching profession: Relations with school context, feeling of belonging, and emotional exhaustion. Teaching and Teacher Education 27, 1029-1038. doi:10.1016/j. tate.2011.04.001

Stephanou, G., Gkavras, G., \& Doulkeridou, M. (2013). The role of teachers' self- and collective-efficacy beliefs on their job satisfaction and experienced emotions in school. Scientific Research Psychology, 4(3), 268-278. doi: 10.4236/psych.2013.43A040

Takahashi, S. (2011). Co-constructing efficacy: A "communities of practice" perspective on teachers' efficacy beliefs. Teaching and Teacher Education, 27, 732-741. doi:10.1016/j.tate.2010.12.002

Tschannen-Moran, M., \& Barr, M. (2004). Fostering student learning: The relationship of collective teacher efficacy and student achievement. Leadership \& Policy in Schools, 3, 189-209. doi: 10.1080/15700760490503706

Tschannen-Moran, M., \& Woolfolk Hoy, A. (2006). The differential antecedents of self-efficacy beliefs of novice and experienced teachers. Teaching and Teacher Education, 23, 944-956. doi:10.1016/j. tate.2006.05.003 
Ware, H., \& Kitsantas, A. (2007). Teacher and collective efficacy beliefs as predictors of professional commitment. Journal of Education Research, 100, 303-310. Recuperado de http://eric.ed.gov/?id=EJ767719

Weiner, B. (1984). Principles for a theory of student motivation and their application within an attributional framework. Em R. Ames \& C. Ames (Eds.) Research on Motivation in Education. Vol. 1: Student Motivation. (p. 15-38). New York: Academic Press.

Woolfolk Hoy, A., \& Spero, R.B. (2005). Changes in teacher efficacy during the early years of teaching: A comparison of four measures. Teaching and Teacher Education, 21, 343-356. doi:10.1016/j. tate.2005.01.007

Zambo, R., \& Zambo, D. (2008). The impact of professional development in mathematics on teachers' individual and collective efficacy: The stigma of underperforming. Teacher Education Quarterly, 35(1), 159-168. Recuperado de http://files.eric.ed.gov/ fulltext/EJ810663.pdf

Recebido em: 23/03/2015

Reformulado em: $31 / 05 / 2015$

Aprovado em: 02/06/2015

Nota dos autores:

O presente estudo teve financiamento da CAPES.

Sobre os autores:

Karina Botti-Manoel é pedagoga, com mestrado em Educação e, atualmente, é professora no Ensino Fundamental. E-mail:ka_botti@hotmail.com

José Aloyseo Bzuneck tem doutorado em Psicologia do Escolar pela USP, pós-doutorado pela UNICAMP e atua como professor sênior no Programa de Pós-Graduação em Educação da Universidade Estadual de Londrina.

E-mail:bzuneck@sercomtel.com.br

Fabio Alexandre Pereira Scacchetti é engenheiro têxtil, mestre em Educação pela Universidade Estadual de Londrina, com doutorando na Universidade do Minho, Portugal, e professor assistente do curso de Engenharia Têxtil na Universidade Tecnológica Federal do Paraná.

E-mail: fabioscacchetti@hotmail.com

Contato com os autores:

Karina Botti-Manoel

Rua Jerusalém, 300, ap. 1102

CEP: 86050-520

Londrina-PR, Brasil 